\title{
A tipificação do crime de feminicídio como medida para o enfrentamento da violência contra
}

\section{a mulher}

\section{The criminalization of feminicide as a measure to face violence against women}

\author{
Rafaela Ferreira França ${ }^{1}$, Roberto Carvalho Veloso ${ }^{2}$
}

RESUMO: O feminicídio é um fenômeno social, caracterizado pela violência que exprime relações de gênero predominantemente hierárquicas e desiguais, antecedido por outros episódios, a exemplo de abusos físicos e psicológicos, que sujeitam as mulheres a uma lógica de soberania masculina e a um padrão cultural de submissão aprendido ao longo de gerações. A abordagem, adotada neste trabalho, não tem enfoque na prevenção, mas sim na busca efetiva pelo enfrentamento da impunidade. O propósito deste artigo é desmistificar o entendimento de que falar de feminicídio é unicamente abordar um novo tipo penal ou exigir do Estado algum tipo de incremento específico da legislação. Nesse contexto, o feminicídio, como nova qualificadora do homicídio, é apenas um dos aspectos do debate sobre o problema, e manifesta um possível tipo de resposta para o enfrentamento desse fenômeno social, sem exprimir a integralidade, mas é, também, elemento fundamental, para prosseguir neste caminho árduo, que abrange o enfrentamento do estágio letal da violência de gênero executado contra as mulheres. O presente trabalho também irá apresentar as correntes que exibem as vantagens e as desvantagens da tipificação, ao discutir se o fenômeno é suficiente para a redução de ocorrências de violência contra a mulher.

PALAVRAS-CHAVE: feminicídio; violência de gênero; lei nº 13.104/2015.

ABSTRACT: The feminicide is a social phenomenon characterized by violence that expresses predominantly hierarchical and unequal gender relations, which is preceded by other facts, such as physical and psychological abuse, that subject women to a logic of male domination and a cultural pattern of subordination that has been learned over generations. The approach taken in this work does not focus on prevention, but on the effective search for confronting impunity. The purpose of this article is to demystify the understanding that talking about feminicide is only addressing a new criminal type, or to demand from the State some kind of specific increase in criminal legislation. In this context, the feminicide as a new qualifier for homicide is only one aspect of the debate about the problem, it manifests a possible type of response to the confrontation of this social phenomenon, without expressing the wholeness, but it is also a key element in pursuing this hard path, which involves confronting the lethal stage of gender-based violence against women. The present paper will also present the currents that show the advantages and disadvantages of typifying, discussing whether the phenomenon is enough to reduce cases of violence against women.

KEY WORDS: feminicide; gender violence; law n. 13.104/2015.

\footnotetext{
${ }^{1}$ Acadêmica do $6^{\circ}$ período do curso de Direito da Universidade Ceuma. Voluntária do Núcleo de Estudos em Municipalidades e Direito (Nemud).E-mail: rafafranca.enf@ hotmail.com.

${ }^{2}$ Docente do curso de Direito da Universidade Ceuma. Doutor em Direito pela Universidade Federal de Pernambuco; Juiz Federal. Ex-Presidente da Associação dos Juízes Federais do Brasil/AJUFE. E-mail:velosrc@uol.com.br
} 


\section{Introdução}

No presente artigo, elaborado pelo Núcleo de Estudos em Municipalidades e Direito (Nemud) da Universidade Ceuma, será abordado o fenômeno da tipificação jurídica do feminicídio, modalidade de homicídio qualificado, como medida para o enfrentamento da violência contra a mulher.

Nos ensinamentos de Hungria (1979, p. 227), o direito de viver não é apenas um direito sobre a vida, mas à vida, e os demais seres humanos são obrigados a respeitar a nossa forma de viver, com diferenças, peculiaridades que tornam cada indivíduo único em uma sociedade. $\mathrm{O}$ direito à vida está consagrado no artigo $5^{\circ}$, caput, da Constituição Federal de 1988, sendo a sua proteção um verdadeiro imperativo jurídico.

Em razão de sua importância, o direito à vida também recebeu a devida proteção legal no Capítulo I, Parte Especial, do Código Penal, que definiu os crimes contra a vida (BITENCOURT, 2012, p. 49-50), dentre os quais se encontram o homicídio (art. 121), composto pelo núcleo "matar", que admite qualquer meio de execução hábil a produzir o resultado, e o elemento objetivo “alguém”, entendido como qualquer ser humano.

Apesar do amparo constitucional e legal, o "Mapa da Violência 2015: homicídios de mulheres no Brasil" (WAISELFISZ, 2015) demonstrou que o Brasil possui uma taxa de 4,8 mortes por 100.000 mulheres (2,4 vezes maior que a taxa média internacional), sendo o quinto país com maior número de mulheres mortas em razão de gênero. Para se ter uma ideia da gravidade da questão, somente em 2013, último ano com dados publicados, 4.762 mulheres tiveram suas vidas ceifadas.

No ano em que a desonrosa posição foi alcançada, o Brasil também promulgou a Lei 13.104/15 com o objetivo de trazer maior segurança e proteção às mulheres em situação de risco. Segundo Waiselfisz (2015), "essa Lei tipificou o crime de feminicídio, definindo-o, em síntese, como o homicídio de mulher por razões de gênero quando envolve violência doméstica e familiar, menosprezo ou discriminação à condição de mulher".

Lagarde (2006, p. 221), responsável por introduzir o termo feminicídio no meio acadêmico, afirmou ter escolhido esse vocábulo justamente por representar bem o fator da impunidade, em virtude de ausências legais e de políticas de governo, que geravam uma convivência insegura para as mulheres, ao colocá-las em risco e favorecer o conjunto de crimes praticados por razões de gênero.

Para o supracitado autor, o feminicídio é consequência da posição de supremacia que o homem exerce em relação às mulheres: 
O feminicídio não era apenas uma violência exercida por homens contra mulheres, mas por homens em posição de supremacia social, sexual, jurídica, econômica, política, ideológica e de todo tipo, sobre mulheres em condições de desigualdade, de subordinação, de exploração ou de opressão, e com a particularidade da exclusão. (LAGARDE, P. 221, 2006).

Percebe-se, portanto, que a violência doméstica e familiar contra a mulher, antes vista como um problema privado, no qual o Estado não deveria intervir, passou a ser encarada como uma forma de violação dos direitos humanos, ao merecer especial atenção e repressão estatal, por abalar as relações jurídicas de enorme relevância, ou seja, ligadas à liberdade, à vida e à igualdade.

Nesse contexto, muito se tem debatido acerca dos limites das leis penais para responder ao crime em questão. O movimento feminista encara o feminicídio como causa qualificadora do crime de homicídio e defende o seu agravamento. Por outro lado, tem sido unânime o entendimento de que a lei penal não é adequada para nenhum delito, mas que deve ser empregada quando se reconhece a gravidade da questão, ainda que não seja suficiente para assegurar a prevenção do fenômeno ou a punição dos casos.

As opiniões proferidas, durante a reunião do Comitê Latino-Americano para a Defesa da Mulher, ratificam esse entendimento. Para Carmen Anthony: "como criminólogas, sabemos que o direito penal não previne nenhum tipo de conduta ilícita" (ANTHONY apud CLADEM, 2011, p.11). Já Berterame, por sua vez, questionou: "por que colocará o feminismo tantas energias em algo que não vai gerar nenhuma mudança, nem vai prevenir as matanças e mortes de mulheres?" (BERTERAME apud CLADEM, 2011, p.214).

Como se pode perceber, esta é uma questão conhecida e enfrentada tanto pelos movimentos de mulheres quanto de feministas. Portanto, não se pode falar em ingenuidade ou desconhecimento dos grupos que reivindicam o agravamento penal do fenômeno. Existe, em realidade, uma aposta na necessidade de não se descartar o agravamento do homicídio como uma das possíveis medidas, e não como solução única.

A argumentação da prevenção não está em discussão, mas sim a busca efetiva pelo enfrentamento da impunidade. Falar em punição pode ser uma tarefa árdua, mas este é o limite do direito penal evocado em eventos que revelam crueldade e ofensa aos direitos humanos. A violência, em análise, não é algo menor ou com irrelevante potencial ofensivo. Trata-se de um fenômeno de difícil, mas de necessário enfrentamento, que passa pelas vias da penalidade. Assim, um tratamento penal apropriado pode ser capaz de direcionar políticas criminais e políticas públicas como medidas de enfrentamento do feminicídio. 
A análise da Lei do Feminicídio ( $\mathrm{n}^{\circ}$ 13.104/2015) objetiva a investigação de sua aplicabilidade no direito penal brasileiro. A lei criou um tipo qualificado de homicídio com o objetivo de dar maior visibilidade aos homicídios cometidos contra as mulheres, em razão de gênero, por conta da tendência de crescimento no índice de ocorrências desse tipo de atrocidade.

Assim, o propósito deste artigo é propiciar a compreensão sobre o feminicídio, e identificálo como fenômeno social que exprime a letalidade da violência de gênero, além de desmistificar o entendimento de que falar de feminicídio é, unicamente, abordar um novo tipo penal ou exigir do Estado algum tipo de incremento específico na legislação penal.

Por fim, deve-se ressaltar que o feminicídio, como nova qualificadora do homicídio, é apenas um dos aspectos do debate, que apresenta uma possível resposta para o enfrentamento desse fenômeno social, sem, no entanto, exprimir a sua integralidade. Apesar disso, mostra-se fundamental para a persecução do objetivo maior que abrange o combate do estágio letal da violência de gênero praticada contra as mulheres.

\section{Feminicídio}

\subsection{Conceito}

O relatório final da Comissão Parlamentar Mista de Inquérito sobre Violência contra a Mulher (CPMI-VCM), datado de 2013, delineou os principais aspectos do feminicídio, e estabeleceu tratar-se da última instância de controle da mulher pelo homem, que se expressa por meio de afirmação irrestrita de posse, ao igualá-la a um objeto, como subjugação de sua intimidade e identidade, por meio de violência sexual associada ao assassinato (BRASIL, 2013, p. 1003).

Portanto, o feminicídio representaria o último estágio de um processo contínuo de violência, que culmina na morte da mulher, cujo caráter violento evidenciaria o predomínio de relações de gênero hierárquicas e desiguais, sendo precedido por outros eventos, tais como abusos físicos e psicológicos, que tentam submeter a mulher a uma lógica de dominação masculina (BANDEIRA apud. DOSSIÊ, 2015).

\subsection{Contexto histórico}

A pesquisadora Minayo (2006, p. 14) afirma que "a maior parte das dificuldades para conceituar a violência vem do fato de ela ser um fenômeno da ordem do vivido, cujas manifestações provocam ou são provocadas por uma forte carga emocional de quem a comete, de quem a sofre e 
de quem a presencia”. Assim, para se entender a sua dinâmica, na realidade brasileira, deve-se compreender a visão da sociedade a respeito do tema, posto que os eventos violentos sempre passam pelo julgamento moral da sociedade.

Segundo Minayo (2006, p. 13), o vocábulo violência "vem da palavra vis que quer dizer força e se refere às noções de constrangimento e de uso da superioridade física sobre o outro". De acordo com a autora, embora o vocábulo pareça neutro em seu sentido material, "quem analisa os eventos violentos descobre que eles se referem a conflitos de autoridade, a lutas pelo poder e a vontade de domínio, de posse e de aniquilamento do outro ou de seus bens".

É nesse sentido que se pode afirmar haver modalidades de violência construídas historicamente, que perduram nas sociedades, e encontram-se naturalizadas, posto que os sujeitos que as cometem acreditam exibir um comportamento absolutamente normal, logo, tolerável e minimizável. A violência, pautada no gênero, amolda-se nessa categoria (MINAYO, 2010, p. 23), sendo a violência doméstica e familiar uma de suas expressões mais cruéis.

Segundo o entendimento de Minayo (2010), a análise da violência, pautada no gênero, possibilita aos historiadores uma melhor compreensão das relações de poder. O gênero acaba por representar o primeiro modo de se dar significado às relações de poder, sendo a separação entre os sexos uma das formas de percepção das relações sociais que o compõem. (TORRÃO FILHO, 2004, p. 134).

Com a finalidade de se aprofundar na explanação referente à violência doméstica, é fundamental delimitar o conceito de gênero que a engloba. De acordo com Scott (1995, p. 79), “o gênero é uma categoria útil à história, não apenas à história das mulheres, perpassando as concepções unicamente oposicionistas aos determinismos biológicos entre homem-mulher, mas especialmente mostrando-se ser uma categoria em relacionamento recíproco com o poder".

A violência de gênero é, por vezes, compreendida como um fenômeno histórico e socialmente construído. Para Lagarde (2011, p. 80), existem particularidades de gênero "surgidas no processo histórico de relação entre biologia-sociedade-cultura, sexo-gênero e corpo vivido-trabalhoconteúdos da vida". O autor também assevera que "a mulher não tem existência material, é uma categoria produto da abstração de um conjunto de características que compartilham todas as mulheres".

Nesse contexto, insta consignar que os homicídios de mulheres são denunciados há décadas, pelo movimento feminista, como intencionais e não ocasionais. Além disso, sabe-se que as taxas de homicídios de mulheres são extremamente inferiores às taxas masculinas; por isso, é 
importante mencionar que a inserção das mulheres, no universo da criminalidade e da violência, também é muito menor.

Depreende-se, então, que a própria subjetividade de mulheres e homens, agredidas e agressores, acaba por ser construída socialmente, tendo forte demarcação pelos binarismos sexuais impostos no seio das relações sociais. Ora, os membros da sociedade constroem suas identidades, pautados nos lugares que ocupam nas relações sociais, sendo estas alocações fortemente influenciadas pelo processo de dominação-exploração "que assegura o poder dos ricos, dos homens e dos brancos" (SAFFIOTI, 2003, p. 29).

Destarte, deve-se considerar a condição desigual que homens e mulheres vivenciam socialmente, sob pena dos elementos constituintes do feminicídio serem desarticulados e compreendidos de maneira completamente desvinculada. Fora a desproporcionalidade no número de mortes de homens e mulheres, chama atenção a condição de gênero da vítima, que é fundamental para a sua morte, isto é, a mulher morre porque é mulher num contexto de extrema violência de gênero.

Diante desse cenário, fez-se necessária a elaboração de leis com o objetivo específico de garantir a proteção de mulheres em condição de violência de gênero. No Brasil, a Lei Maria da Penha, promulgada no ano de 2006, constituiu um marco fundamental no enfrentamento desse quadro, pois reconheceu-se, definitivamente, a violência de gênero, no ambiente doméstico, como violação dos direitos humanos das mulheres (LIMA, 2016).

Apesar do esforço significativo, Garcia (2015) compreende que a Lei Maria da Penha não foi capaz de reduzir as taxas de mortalidade relacionadas com esse tipo de agressão:

\footnotetext{
Constatou-se que não houve impacto, ou seja, não houve redução das taxas anuais de mortalidade, comparando-se os períodos antes e depois da vigência da Lei. As taxas de mortalidade por 100 mil mulheres foram 5,28 no período 2001-2006 (antes) e 5,22 em 2007-2011 (depois). Observou-se sutil decréscimo da taxa no ano 2007, imediatamente após a vigência da Lei e, nos últimos anos, o retorno desses valores aos patamares registrados no início do período (GARCIA, 2015).
}

O índice exorbitante de mortes de mulheres brasileiras revela a existência de um problema crônico. Nesse sentido, o relatório do Ipea (Instituto de Pesquisa Econômica Aplicada), datado de 2013, apresenta o quadro de feminicídios na última década, e informa que, entre os anos de 2001 e 2011, mais de 50 mil feminicídios ocorreram no país, contabilizando-se, aproximadamente, 5.000 mortes por ano (GARCIA, 2015).

Com a inserção da qualificadora do feminicídio no Código Penal, o Brasil foi o primeiro país da América Latina a implementar uma legislação com o objetivo específico de confrontar o 
assassinato de mulheres, ao acompanhar a orientação de soluções institucionais voltadas para fixação de penas mais elevadas a tais eventos.

Por derradeiro, enfatiza-se que uma parcela significativa da doutrina e dos operadores do direito expõe críticas contundentes, ante os mais diferentes argumentos, à tipificação do feminicídio como o melhor método de combater a violência contra a mulher, ao reconhecer que se repetirá o fenômeno simbólico que se deu com a Lei Maria da Penha.

\subsection{As vantagens e as desvantagens da tipificação}

O principal argumento utilizado, por quem defende a tipificação do feminicídio, é a possibilidade de tornar visível a existência de homicídio de mulheres por razões de gênero para que o público conheça e se sensibilize com a situação dessas mulheres, e, também, contribua para a mudança da mentalidade patriarcal ainda hoje existente (CLADEM, 2012, p. 177-229).

E assim, ao torná-lo visível, os defensores da tipificação acreditam que o Estado se veria obrigado a tomar providências no sentido de evitar a morte de mulheres, por meio da criação de políticas públicas adequadas de prevenção e erradicação da violência, bem como da persecução penal do agressor, ao assumir sua responsabilidade em casos de omissão, negligência ou intervenção ineficaz (CLADEM, 2012, p. 177-229).

Afirmam também que, embora a norma jurídica do homicídio possa ser adotada na persecução penal de quem tira a vida de uma mulher por razões de gênero, não é possível visualizar o contexto em que as mortes se deram, tampouco o caráter social e a generalizado da violência, baseada no gênero, uma vez que as ocorrências são registradas, simplesmente, como homicídios, resultantes de problemas passionais (CLADEM, 2012, p. 177-229).

Ademais, os defensores da criminalização do feminicídio também asseveram que, quando se fala de um delito tão grave, como a morte de uma mulher, por razões de gênero, reconhecido pelos principais instrumentos jurídicos internacionais, o conceito de intervenção mínima do Direito Penal passa a ser inadmissível. Há quem afirme, ainda, que o Direito Penal, como ultima ratio, é um mito, em virtude da historicidade da luta dos movimentos sociais (CLADEM, 2012, p. 177-229).

Por outro lado, as opiniões contrárias à criminalização se sustentam na falta de efetividade do Direito Penal, ao arguir que nem o problema da violência contra as mulheres nem a impunidade se solucionam com a criação de novas figuras penais; sendo esse ramo do direito incapaz de inibir comportamentos violadores dos direitos das mulheres, além de não contribuir, também, para exercer a função ressocializadora do infrator (CLADEM, 2012, p. 177-229). 
Dessa forma, expõem que um tipo penal não é capaz de garantir uma política criminal ou uma mudança da interpretação jurídica, pois há a necessidade de políticas específicas para cada grupo de mulheres, que se encontra em situações distintas. Também discordam do fato de certas legislações preverem, como sujeito ativo, apenas os homens, pois desconsideram o assassinato de lésbicas por suas parceiras, ao afirmar que a tipificação do feminicídio poderia abrir caminho para o Direito Penal do autor, e isso tiraria o foco da valoração da conduta praticada, criando uma lógica binária de culpáveis e vítimas (CLADEM, 2012, p. 177-229).

Assim, verifica-se que os argumentos das duas vertentes são plausíveis. Existem vantagens e desvantagens nos dois âmbitos. A solução, para a harmonização da tipificação do feminicídio com o Direito Penal mínimo, pode ser encontrada no Garantismo Penal, em seu aspecto positivo.

Enquanto o Garantismo Negativo funciona como limite ao jus puniendi do Estado (FERRAJOLI, 2002, p. 30), o Garantismo Positivo preceitua que o Estado deve proteger os direitos humanos contra as diferentes formas de sua violação (BARATTA, 1997, p. 66). Para Borges (2012, p. 82), o critério, para a legitimação da intervenção penal, estaria na objetividade jurídica da proteção estatal, que, no caso de violação dos direitos humanos, seria a vulnerabilidade difusa dos grupos humanos discriminados ou violados.

Em conformidade com Borges (2012, p. 84), o princípio da subsidiariedade é um dos limites para que nem toda forma de violação implique uma hiperinflação da legislação penal. O autor afirma que deveria haver uma crescente sensibilização sociocultural sobre o alcance e a natureza dos direitos humanos, ao destacar que a proteção a estes direitos deve preponderar na fase pré-violatória.

Contudo, não sendo possível evitar a violação, Borges (2012, p. 86) afirma que o Estado deveria assegurar a tutela penal na fase pós-violatória, tendo como critério de legitimidade, para a sua intervenção, a vulnerabilidade dos titulares desses direitos, não uma vulnerabilidade circunstancial, mas constante e estrutural, resultado de violações sistemáticas, associadas à impunidade dos respectivos agressores.

Com o fulcro nesse fundamento, o Direito Penal estaria legitimado a intervir nas causas de homicídios por razão de gênero, devido à vulnerabilidade das mulheres, à prática sistemática das mortes e à anuência ou tolerância do Estado. Contudo, a intervenção deveria ocorrer de forma racional, em conformidade com a realidade de cada país, evitando-se tipos abertos, que poderiam dar causa à discricionariedade ou à subjetividade dos juízes, ao lesar os princípios da taxatividade e da segurança jurídica. 
Ademais, tal tutela penal deveria vir dentro de uma política integral de prevenção, proteção e punição. Somente tipificar o feminicídio e aumentar as penas para quem mata uma mulher, por razões de gênero, não será a solução. Exemplo disso é a incapacidade, em reduzir delitos, apresentada pela política criminal de cunho eficientista, desenvolvida pelos Estados Unidos, que pretendia combater a violência com a maximização do aparelho policial e a criminalização de novas condutas (LOTKE, 1998, p. 39-50).

Finalmente, deve-se dar importância às políticas públicas que imponham ao Estado investir em campanhas de sensibilização, capacitação contínua, garantia do acesso à Justiça, desenvolvimento de planos, programas e estratégias setoriais e territoriais, promoção de amplos modelos de prevenção que possuam enfoque na proteção da mulher contra qualquer tipo agressão.

\section{Resultados e discussões}

Conforme apresentado no Mapa da Violência 2015, o sociólogo Waiselfisz (2015, p. 8) apurou que, entre 2003 e 2013, o número de mulheres, vítimas de homicídio, cresceu de 3.937 para 4.762. Ao considerar-se esses dados, verifica-se que houve um aumento de $8,8 \%$ na taxa de homicídios de mulheres em relação ao crescimento da população feminina no período.

Com o advento da Lei Maria da Penha, houve uma pequena redução na taxa de homicídios de mulheres, o supracitado estudo aponta uma percentagem de 4,2 em 2006 e de 3,9 em 2007, porém a redução não se estabilizou ao longo do tempo. A taxa voltou a crescer a partir de 2008, quando retornou ao patamar de 4,2\%, e chegou a 4,8\% em 2012. A obra também delineou o perfil das vítimas mais vulneráveis aos casos de homicídio: mulheres negras (pretas e pardas) na faixa etária compreendida entre 18 e 30 anos (WAISELFISZ, 2015).

Fora isso, conforme expresso em Brasil (2017, p. 44), que consolidou o número total de casos de conhecimento e de execução penal em feminicídio no ano de 2016, foram iniciados 4.289 casos de execução penal em feminicídio, sentenciados 540 processos, baixados outros 3.927 e estiveram pendentes de decisão cerca de 6.213 casos. Portanto, o percentual de processos sentenciados de execução penal, em feminicídio, foi da ordem de $12,60 \%$, que, como se sabe, não é suficiente para fazer frente ao volume de novas ocorrências.

Por fim, o Mapa da Violência de 2015 indica que os Estados com maiores índices de assassinatos de mulheres, em relação ao total da população feminina, são: Roraima, Espírito Santo, Goiás, Alagoas e Acre. De maneira oposta, as menores taxas foram averiguadas em São Paulo, Piauí e Santa Catarina (WAISELFISZ, 2015). Os números demonstram que o feminicídio tem uma 
incidência desigual no território brasileiro, muito provavelmente em virtude da deficiência de políticas públicas locais voltadas para o combate e para a prevenção da agressão contra a mulher.

\section{Conclusão}

Tratar sobre o homicídio de mulheres, sob a perspectiva de gênero, requer um significativo envolvimento - não apenas do Estado, mas também da sociedade - para a supressão efetiva desse tipo de ocorrência. Como apresentado, nas seções anteriores, é praticamente impossível falar a respeito desse fenômeno apenas do ponto de vista criminal.

O enfoque criminal não abrange as causas e as medidas necessárias para a sua prevenção tanto no âmbito público quanto no espaço privado. Assim, é imprescindível uma abordagem mais ampla dos vários fatores do problema, ou seja, dar visibilidade a ele, com o objetivo de incluir o feminicídio no quadro de problemas que assolam a sociedade, ao expressar que a violência contra as mulheres é inaceitável.

Nesse sentido, buscou-se demonstrar a importância de não subsumir o fenômeno ao tipo penal, ou seja, não caracterizar o feminicídio apenas como uma demanda estatal por um novo tipo penal ou por um tratamento penal específico. O feminicídio é um fenômeno social amplo e complexo e a sua qualificação, no Código Penal, é apenas uma das possibilidades para o seu enfrentamento.

Portanto, o enfrentamento da violência contra as mulheres não reclama do poder público apenas esforços legais, mas também políticas públicas, em longo prazo, desenvolvidas em virtude da compreensão de como esse fenômeno se originou, dos agentes envolvidos e das necessidades singulares das mulheres, ao buscar respostas para a violência segundo uma ótica mais abrangente, direcionada para a atenuação dos impactos da desigualdade e da exclusão.

\section{Referências}

BARATTA, Alessandro. Defesa dos direitos humanos e política criminal: Discursos Sediciosos. Rio de Janeiro, p. 66, 1997.

BANDEIRA, Lourdes. Apud Dossiê: Violência contra as Mulheres. 2015. Disponível em: <http://www.agenciapatriciagalvao.org.br/dossie/violencias/feminicidio/>. Acesso em: $10 \mathrm{fev}$. 2018.

BITENCOURT, Cezar Roberto. Tratado de Direito Penal, 2: parte especial: dos crimes contra a pessoa. 12a edição. São Paulo: Saraiva, 2012. 
BORGES, Paulo César Correa. A tutela penal dos direitos humanos. Revista Espaço Acadêmico, Maringá, n. 134, p. 82-88, julho 2012.

BRASIL. Conselho Nacional de Justiça. O Poder Judiciário na aplicação da Lei Maria da Penha. Brasília, 2017. Disponível em:

http://www.cnj.jus.br/files/conteudo/arquivo/2017/10/ba9a59b474f22bbdbf7cd4f7e3829aa6.pdf. Acesso em: 18 jul. 2017.

BRASIL, Senado Federal. Comissão Parlamentar Mista de Inquérito. Relatório Final. Brasília, julho de 2013.

CLADEM. Contribuciones al debate sobre la tipificación penal del femicidio/ feminicídio. Lima, 2011. Disponível em:

http://www.compromissoeatitude.org.br/wpcontent/uploads/2013/10/CLADEM_TipificacaoFemini cidio2012.pdf. Acesso em: 14 de julho de 2017.

FERRAJOLI, Luigi. Direito e razão: teoria do garantismo penal. São Paulo: Revista dos Tribunais, 2002.

GARCIA, Leila Posenato et al. Violência contra a mulher: feminicídios no Brasil. Instituto de Pesquisa Econômica Aplicada - IPEA. 2013. Disponível em:

<http://www.ipea.gov.br/portal/images/stores/PDFs/130925_sum_estudo_feminicídio_leilagarcia.p df. Acesso em 13 out. 2017.

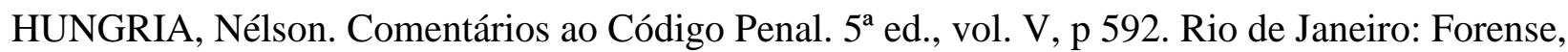
1979.

LAGARDE, Marcela y de los Ríos. Del femicidio al feminicidio. Desde el jardín de Freud. Revista de Psicoanálisis. Bogotá: n. 6, p. 216-225, 2006.

LAGARDE, Marcela. "Por la vida y la libertad de las mujeres: Fin al feminicidio Día V- Juárez". 2011. Disponível em: http://www.cimacnoticias.com.mx/especi ales/comision/diavlagarde.htm. Acesso em 17 de novembro de 2017.

LIMA, Amanda Gabriela Gomes. Uma Breve Análise do Feminicídio como Qualificadora Penal sob a Perspectiva de uma Criminologia Feminista. I Encontro de Pesquisas Judiciárias: Poder Judiciário: estrutura, desafios e concretização de direitos. 2016. Disponível em:

<http://enpejud.tjal.jus.br/index.php/exmpteste01/article/view/176/21> Acessado em: 15 fev. 2018.

LOTKE, Eric. A dignidade humana e o sistema de justiça criminal nos EUA. Traduzido por Ana Sofia Schmidt de Oliveira. Revista Brasileira de Ciências Criminais, São Paulo, ano 6, n. 24, p. 3950, out./dez.1998.

MINAYO, Maria Cecília de Souza. Violência e Saúde. Rio de Janeiro: Editora FIOCRUZ. 132 p. (Coleção Temas em Saúde). 2006. 
. Conceitos, teorias e tipologias de violência: a violência faz mal à saúde. In: NJAINE,

Kathie; ASSIS, Simone Gonçalves de; CONSTANTINO, Patrícia (org.). Impactos da Violência na Saúde. Rio de Janeiro: Editora Fiocruz, 2010.

SAFFIOTI, Heleieth . Violência estrutural e de gênero - Mulher gosta de apanhar?. In:

PRESIDÊNCIA DA REPÚBLICA. Programa de Prevenção, Assistência e Combate à Violência Contra Mulher - Plano Nacional: Diálogos sobre Violência Doméstica e de Gênero - construindo políticas públicas, p. 27-38, 2003.

SCOTT, Joan W. Gênero: uma categoria útil de análise histórica. Educação e Realidade. Porto Alegre, vol. 20, p. 71-99, n. 2, jul./dez. 1995.

TORRÃO FILHO, Amílcar. Uma questão de gênero: onde o masculino e o feminino se cruzam. Caderno Pagu, p. 127-152. Campinas, São Paulo. 2005.

WAISELFISZ, Júlio Jacobo. Mapa da violência 2015: Homicídios de mulheres no Brasil. Brasília: Flacso; 2015. Disponível em: http://www.mapadaviolencia.org.br/ pdf2015/MapaViolencia_2015_mulheres.pdf. Acesso em: 13 de dezembro de 2017. 